\title{
ENTRE KAFKA E STENDHAL: CRÍTICA LITERÁRIA E HISTÓRIA NA LITERATURA DOCUMENTAL DE VERTIGEM, DE W. G. SEBALD
}

\author{
Carla Lavorati ${ }^{1}$ \\ Rosani Ketzer Umbach ${ }^{2}$
}

\begin{abstract}
Resumo: Vertigem, lançado na Alemanha em 1990, inaugura as narrativas em prosa de W. G. Sebald. A obra é dividida em quatro partes, duas delas são inspiradas na vida de Stendhal e Kafka e se assemelham a ensaios críticos, as outras duas estruturam-se a partir de um narrador em primeira pessoa. No espólio do autor, em Deutsches Literaturarchiv Marbach, Alemanha, é possível entrar em contato com as fontes de pesquisa utilizadas na escrita de Vertigem e observar influências do processo de ficcionalização dos documentos. Exemplo disso são duas matérias jornalísticas: a primeira, intitulada "Kafka in Riva, 1913", de autoria de Anthony Northey, publicado no Neue Zürcher Zeitung, jornal semanário na sessão "Literatur und Kunst", datada de 24 de abril de 1987; e a matéria "Die Gnadenlosen", publicada no jornal alemão Die Zeit, em 5 de dezembro de 1986, de autoria de Erwin Brunner. Ambas compõem referências extraliterárias, principalmente pelo modo como o processo de inserção [Einbetten] das fontes coaduna-se com um entrelaçamento [Einschachten] das histórias dos personagens e do narrador. Portanto, a análise será centrada nos documentos arquivados pelo autor-narrador e no modo como a inscrição dos arquivos torna-se uma forma de trazê-los novamente ao uso, metamorfoseados em novas formas de ler e representar a realidade.
\end{abstract}

Palavras-chave: W. G. Sebald, Vertigem, Arquivos, Ética, Subjetividade.

Abstract: Vertigo, published in 1990 in Germany, begins W. G. Sebald's prose narratives. The work is divided into four parts, two of which are inspired by the life of Stendhal and Kafka and resemble critical essays, the other two are based on a first-person narrator. In the author's collection, in Deutsches Literaturarchiv Marbach, Germany, it is possible to contact the research sources used in Vertigo's writing and to observe influences of the process of ficionalization of documents. As an example there are two journalistic articles: the first, entitled "Kafka in Riva, 1913", by Anthony Northey, published in the "Hamburg weekly newspaper Neue Zürcher Zeitung", at the "Literatur und Kunst" session, dated April 24, 1987; and the second, "Die Gnadenlosen", published in the "German newspaper Die Zeit", on December 5, 1986, by Erwin Brunner. Both make extra literary references, mainly for the way the process of inserting [Einbetten] sources fits in with an [Einschachten] entanglement of the stories of the characters and the narrator. Therefore, the analysis will be centered on the documents archived by the narrator-author and on how the inscription of the archives becomes a way to bring them back to use, transformed into new ways of reading and representing reality.

Key Words: W. G. Sebald, Vertigem, Archives, Ethics, Subjectivity.

1 Doutora em Estudos Literários no Programa de Pós-Graduação em Letras na UFSM. E-mail: carlalavorati@gmail.com 2 Professora Titular do Departamento de Letras Estrangeiras Modernas da UFSM e Pesquisadora do CNPq. E-mail: rosani. umbach@ufsm.br. 
As pinturas de Pisanello tinham despertado em mim já havia muitos anos o desejo de abrir mão de tudo, menos da visão. Não é apenas o realismo de sua arte, altissimamente desenvolvido para a época, o que me atrai em Pisanello, mas a maneira como consegue criar o efeito do real sem sugerir profundidade, numa superfície basicamente rasa, na qual todos - a protagonistas e coadjuvantes, aos pássaros no céu, à floresta verde e a cada uma das folhas - é concedido igual e pleno direito de existir.

(Sebald, Vertigem)

Primeira narrativa em prosa de Sebald, lançado em 1990, na Alemanha, Vertigem é dividido em quatro partes: "Beyleou o amor, essa criatura agridoce e irresistível" que é inspirado na autobiografia de Stendhal - intitulada Vie de Henry Brulard; “All'Estero", um texto autobiográfico no qual o narrador conta sobre uma viagem pela Itália (Viena, Veneza e Verona), nos anos de 1980, (tal qual realizada também pelo autor); “A vilegiatura de Dr. K. em Riva" que é uma espécie de ensaio sobre episódios da vida de Kafka na cidade de Riva, Itália; e, por último, "Il Ritorno in patria", escrito também em primeira pessoa e com o mesmo tom autobiográfico do segundo capítulo, no qual o autor-narrador volta para sua cidade natal, denominada apenas como W., possível referência a cidade de Wertach, Alemanha, onde Sebald nasceu. Os capítulos dois e quatro, que tratam das viagens do narrador pela Itália e, posteriormente, para a cidade de W., estruturam-se a partir de um narrador em primeira pessoa, diferente do que acontece com os capítulos sobre Stendhal e Kafka, escritos na voz impessoal e que se assemelham ao gênero ensaio crítico.

A ligação entre as histórias, portanto, não se dá a partir do mesmo foco narrativo, o que mantém a unidade da obra é o entrelaçamento, o modo como as camadas de histórias dos personagens encaixam-se umas às outras, produzindo ressonância de sentidos entre elas, o que é responsável pelo efeito de fantasmagoria entre as partes. As ligações entre o narrador e os dois personagens literários se dá a partir de uma cadeia de contiguidade semântica, pois conforme aponta Niehaus (2006, p. 26): "A ligação entre esses dois textos e a figuração de uma mudança entre autor e narrador nas duas outras histórias se faz apenas mais tarde". ${ }^{3}$ Portanto, as histórias que, em um primeiro momento parecem se tratar de narrativas independentes, apresentam uma sequência de coincidências responsáveis pela unidade textual e pelo efeito de fantasmagoria que atravessa o romance.

Dr. K e Henri Beyle são respectivamente Kafka e Stendhal. Em nenhum momento do texto é mencionado seus nomes verdadeiros, a referência ocorre pelo cruzamento das histórias com episódios conhecidos da biografia de ambos os escritores. Entre Beyle, Dr. K. e o narrador são comuns os sentimentos de angústia e desolação, todos são afetados pela solidão e por "fracassos" amorosos, o que é agravado ou é mesmo o resultado das inclinações dos três para atividades de leitura e escrita, nas quais os sentimentos de melancolia facilmente vêm à tona. Essa circunstância faz lembrar o ensaio crítico de Sebald "A descrição da

3 [No original] «Le lien entre ces deux textes et la figuration d'un changeant entre auteur et narrateur, dans les deux autres récits, ne se fait qu'ultérieurement». 
infelicidade: sobre a literatura austríaca de Stifter até Handk" ${ }^{4}$, sobre a relação entre escrita e infelicidade, incluindo um texto sobre Kafka.

Nesse ensaio, voltado para escritores austríacos que não pertenciam ao mainstream da produção germanística, o interesse é pelo limiar entre literatura e psicopatologia, já configurando as áreas de interesse de Sebald e o modo como se posicionou diante da tradição literária. Segundo Schütte (2016), em ensaio sobre a relação de Sebald com a literatura "menor" da Áustria, trata-se de uma “[...] paixão que se dirigiu quase exclusivamente a obras literárias surgidas na margem do território de língua alemã e na periferia do cânone estabelecido" (SCHÜTTE, 2016, p. 9) e que evidencia como o autor manteve suas produções críticas e mesmo sua obra ficcional e poética influenciada por autores marginais, sendo paradigmáticos nesse contexto o escritor esquizofrênico Ernst Herbeck e o cineasta e escritor Herbert Achternbusch.

Retornando às vertigens de Vertigem, consideremos: Stendhal, de 1783 a 1842; Kafka, de 1883 a 1924, Sebald, de 1944 a 2001, e o narrador em 1980; todos com o espírito inclinado à escrita, padecendo de dores e doenças e sentindo um certo deslocamento diante do mundo, acumulando fracassos amorosos e solidão, o que contribui em muitos momentos com o tom de lamento da narrativa, mas isso sem excluir a ironia e o chiste que perpassa a obra e que advém desse olhar sempre deslocado que o autor-narrador direciona para as histórias, para os objetos e para si próprio.

O narrador em primeira pessoa relata a partir de suas lembranças. Os fatos vividos estão localizados no passado e dependem da recordação para voltar à memória e tornarem-se escritura. Em todas as histórias, a memória é problematizada, sendo exposta a sua fragilidade e o modo como o imaginário nela se inscreve, moldando a percepção e os sentimentos e tornando-a passível de falácias e emboscadas. Assim, muitas histórias em Vertigem conduzem, de algum modo, a devaneios; momentos limiares entre o sono e a vigília, a normalidade e a loucura. Esses topos estabelecem uma espécie de espectralidade entre os personagens e entre o narrador e o autor, diluindo as fronteiras do tempo e colocando-os em coexistência, no qual os vivos e os mortos habitam o mesmo espaço de existência.

A reflexão sobre o poder das imagens em falsificar a memória é emblemática na narração da história do personagem Henri Beyle - soldado das tropas de Napoleão -, participante da batalha que ocorreu em 1800, quando mais de trinta e seis mil homens fizeram a legendária travessia dos Alpes, carregados com pesada munição rumo à cidade de Ivrea, na Itália. Sobre a memória desse fatídico dia, o personagem, ao folhear papéis antigos, conta que encontrou "uma gravura intitulada Prospetto d'Ivrea" e foi obrigado a admitir que a imagem que trazia na memória, da cidade ao cair da tarde, não era outra senão a cópia dessa mesma gravura (SEBALD, 2008, p. 10). Assim, a memória foi moldada pela representação da cidade contida na gravura e não pela experiência vivida por Beyle, o que surpreende o personagem, que aconselha que não se compre gravuras de paisagens pelas quais se viaja, “[...] porque uma gravura logo ocuparia todo o espaço da memória que tivéssemos de algo - pode-se mesmo dizer que ela a destruiria"5 (SEBALD, 2008, p. 10). Quando se trata da

4 Die beschreibung des unglücks: zur österreichischen literatur von Stifter bis Handke.

5 [No original] “[...] eine Gravure besetze bald schon den gazen Platz der Erinnerung, die wir von etwas hätten“. 
memória traumática fica ainda mais delicada a relação entre representação e realidade, pois nela a linguagem expõe as dificuldades em narrar experiências limites e inenarráveis. Mas, em Sebald, não se trata da experiência direta do trauma como já discutido, e sim de uma memória que se ocupa da experiência indireta da violência e o faz a partir dos vestígios que dela restaram no presente. De qualquer forma, há o mesmo cuidado para não subscrever o horror, o que demarca uma posição de moralidade autoral. E voltando a Beyle, devemos citar ainda as referências encontradas no espólio sobre o livro Vie de Henry Brulard, que apresenta registros de trechos e imagens que são utilizados por Sebald no capítulo de abertura de Vertigem.

O escritor francês e também o escritor austríaco mantêm com o narrador um diálogo "subterrâneo" no qual as percepções, preocupações e desilusões retornam a partir de um processo de circularidade, no qual uma sequência de coincidências atravessa a diegese. É o que ocorre, por exemplo, com as datas de 1913 e 2013, que funcionam como uma ligação entre a visita de Kafka à cidade de Riva, entremeada pela data de 1980, que é o ano da visita do narrador (e também do autor) à mesma cidade. O ano de 2013 é um futuro ainda a se concretizar (o livro foi publicado em 1990), já que, ao acrescentar 100 anos a data primeira, expande as reticências e potencializa os sentidos do movimento contingente da vida, sugerindo nesse entrelaçamento referencial entre as datas, a dialética do próprio processo de criação e destruição pelo qual a história natural se movimenta. Ao leitor é deixado como último símbolo da narrativa um número; os dois pontos que o isolam da última frase e da página em branco, que antecipa a contracapa, produz um movimento circular na narrativa, que sugere uma possível repetição, uma nova fantasmagoria por vir; o que evidencia o processo de montagem das narrativas de Sebald como ferramenta importante no efeito de criação de sentido do conteúdo da obra. ${ }^{6}$

No espólio do autor, em Deutsches Literaturarchiv Marbach, Alemanha ${ }^{7}$, é possível entrar em contato com as fontes que ele utilizou em suas pesquisas e observar mais influências do processo de ficcionalização de documentos diversos, como imagens, recortes de jornais, anotações manuscritas, desenhos, cópias de livros, almanaques, enciclopédias, fotos, ou seja, uma grande variedade de materiais arquivados pelo próprio autor em vida. Em uma das 14 pastas nas quais está preservado o material referente à narrativa Vertigem, existe uma matéria de autoria de Anthony Northey, publicado no Neue Zürcher Zeitung, jornal semanário na sessão "Literatur und Kunst", datada de 24 de abril de 1987, intitulada "Kafka in Riva, 1913". Trata-se de um texto sobre o período de internamento de Kafka no sanatório do Dr. Von Hartungen, contendo duas fotos do hospital (uma da fachada e outra da sala de refeições) no qual são relatados fatos ocorridos com o escritor e que são ficcionalizados por Sebald a partir de topos, como: solidão, escrita, doença, loucura. A matéria apresenta muitos pontos de contato com o capítulo a "Vilegiatura de Dr. K. em Riva".

A morte do companheiro de internamento do Dr. K., Ludwig von Koch, general aposentado, é ficcionalizada na narrativa de Vertigem apoiando-se nas informações contidas no texto de Anthony Northey, principalmente no que se refere a personalidade de homem

6 Observação: a edição brasileira, publicada pela Companhia das Letras e usada nessa pesquisa, não cita a data de 2013, uma omissão que altera os sentidos mobilizados pelo desfecho original

7 Desde 2004, o arquivo DLA mantém o direito de conservar e expor à pesquisa o conjunto de materiais pertencentes ao autor alemão. Existe um total de 68 caixas que guardam manuscritos, fotografias, documentos pessoais, fichas de pesquisa, recortes de jornais, objetos pessoais, etc., que se encontram parcialmente disponíveis para consulta e ainda o acervo de 1225 volumes de sua biblioteca particular. 
calado do general e ao suicídio que deu fim a sua vida. Segundo a matéria do jornal, Ludwig von Koch teria sido a inspiração para o personagem do caçador Graccus do conto [Der Jäger Gracchus] de Kafka, principalmente quanto ao enterro solitário do general em Riva, e que Kafka transfigurou numa errância pós-morte na qual o caçador segue vagando pelos mares do mundo em uma barca que não conseguiu levá-lo ao outro lado da margem, condenando-o a uma viagem ininterrupta.

Em Vertigem, essa situação é também relatada e julgada pelo narrador como uma “[...] penitência do anseio pelo amor, que sempre assalta o Dr. K., como ele escreve em uma das inúmeras cartas 'Fledernaus' a Felice"8 (SEBALD, 2008, p. 128). Ainda é interessante observar como as informações contidas na matéria do jornal - que em parte está apoiada nas informações contidas em uma carta de Kafka endereçada ao amigo Max Brod, em 28 de setembro de 1913 - são absorvidas pela representação empática do autor, que costuma dar contorno de desajuste e excentricidade aos seus personagens, mas o faz de modo a ressaltar a humanidade de cada um, construindo um discurso que é sempre um aceno de empatia.

Vejamos o trecho da carta de Kafka à Brod, citada no jornal, que faz referências a esse fato: “À mesa, estou sentado entre um velho general (que também não fala nada, mas quando decide conversar é muito inteligente, pelo menos superior a todos os outros) e uma pequena suíça de aparência italiana [...] que se parece infeliz"9 (NORTHEY apud Kafka, 1987, p. 37, tradução nossa). Sobre a moça a qual Kafka refere-se e que na matéria é citada como uma possível paixão sua, não se tem muitas informações. Ainda no início da matéria é salientado que não existem registros detalhados sobre o tempo que Kafka ficou internado em Riva, pois ele se manteve assombrado por um período de baixa produtividade escrita e, mesmo no seu diário, faltam anotações sobre essas três semanas de internamento. Segundo a matéria do jornal de Northey:

Nada se sabe sobre a mulher suíça por quem ele se apaixonou. Era um amor sem esperança. O general, no entanto, pode ter sido Ludwig von Koch, nascido em Meissen em 1847 (mas nativo de Neusiedl, na Hungria), ele serviu no sexto regime Hussar do exército austríaco. Quando ele chegou a Riva, já estava aposentado há vários meses. Na manhã de 3 de outubro, pouco depois das sete horas, de acordo com a investigação posterior da capitania distrital e artigos de jornal, que provavemente também originou outras declarações oficiais, o general Von Koch se retirou para o quarto, pegou sua pistola e disparou. De acordo com o relatório escrito por Christoph von Hartungen na mesma tarde, o general conseguiu disparar um tiro que atingiu ao mesmo tempo seu coração e sua cabeça. Ele foi encontrado deitado em uma poltrona, com um livro em inglês aberto no seu colo. O motivo pelo qual Koch se matou não estava claro. Ele não deixou nenhuma transcrição da depressão extrema. A razão dada foi 'neurastenia'. Um relatório no

\footnotetext{
8 [No original] "[...] wie er in einem seiner zahllosen Fledermausbriefe an Felice schreibt, immer genau dort ergreift, wo scheinbar und gesetzmäßig nichts zu genießen ist“. (SEBALD, 2013, p. 180-181)

9 [No original] “[...] bei Tisch sitze ich zwischen einem alten General (der auch nichts spricht, wenn er sich aber einmal zum Reden entschliest, sehr klug spricht. Zumindest allen anderen überlegen) und einer kleinen italienisch aussehenden [...] die über ihre Nachbarschaft unglücklich ist“.
} 
"Bozener Nachrichten" menciona que ele se mostrou "bastante deprimido", muito taciturno e mesto, escreveu um jornal italiano que, em parte, concorda com as impressões de Kafka. De acordo com o relatório alemão, Koch foi enterrado em um cemitério em Riva, no dia 6 de outubro, depois que seu corpo havia sido colocado na funerária de St. Anna. (NORTHEY, 1987, p. 37, tradução nossa). ${ }^{10}$

Como exposto, é possível estabelecer pontos de contato entre a matéria do jornal e o capítulo de Vertigem e ainda encontrar ressonâncias em outras passagens; assim os indícios de que a criação do personagem Graccus foi inspirada pela morte do general Koch, ainda estabelecem ligações com a "figura" de um caçador que aparece no último capítulo e que havia povoado a imagem do narrador quando criança. Trata-se de um uniforme de general, em decomposição, que teria sido de "[...] um daqueles caçadores austríacos que lutaram contra os franceses como tropas irregulares por volta de 1800" (SEBALD, 2008, p. 174) ${ }^{11}$, ou seja, um caçador fantasma que, sem corporiedade, "vive" de alguma forma através dos vestígios de seu uniforme em decomposição. O encontro do narrador com esse caçador, que mora no sótão de uma casa antiga em W., é descrito como um alegoria do tempo passado. No momento que o narrador, impressionado com o uniforme que o manequim vestia, leva a mão até a manga do casaco para tocá-lo e se certificar da realidade, mas o uniforme se desmancha por completo em pó e seus dedos, agora enegrecidos pela poeira do tecido, trazem-lhe a impressão funesta de que a destruição é algo sempre eminente, "[...] sinal de uma desgraça que nada nesse mundo jamais remediaria” (Ibid. p. 175) ${ }^{12}$. Nota-se, a partir desse primeiro conjunto de referências, o modo como o processo de inserção [Einbetten] de fontes coaduna-se com um entrelaçamento [Einschachten] que produz duplicidades, ressonâncias

10 [No original] "Über die Schweizerin, in die er sich verliebte, weiss man bis heute nichts. Es war eine Liebe ohne Hoffnung. Der General dürfte aber Generalmajor Ludwig von Koch gewesen sein, 1984 in Meisen geboren (aber heimatszuständig nach Neusiedl in Urgarn), diente e rim sechsten Husarenregiment des österreichischen Heeres. Als er in Riva eintraf, war er schon seit einigen Monaten pensioniert. Am Morgen 3 Oktobers kurz nach 7 Uhr, laut der spä teren Ermittlung der Bezirkshauptmannschaft und der wohl aus anderen amtlichen Verlautbarungen entstandenen Zeitungsartikel, zog sich General von Koch in sein Zimmer zurück, nahm seine Pistole und erschoss sich. Dem von Christoph von Hartungen am sellben Nachmittag verfassten Bericht nach gelang es dem General, sich sowohl durch das Herz als auch curch den Kopf zu schiessen. Man fand ihn in einem Fauteuil zusammengesunken mit einem aufgeschlagenen englischen Buch auf dem Schoss. Warum Koch sich umbrachte, war nicht klar; er hinterliess keinerlei Niederschrift. Als Grund wurde 'Neurasthenie' oder Nervenleiden angegeben, eas in diesen Falle wohl eine Umschreibung von extremer Depression darstellen sollte. Ein Bericht in den 'Bozener Nachrichten' erwähnt, dass er sich 'ziemlich niedergeschlagen' gezeit hatte; 'più taciturno e mesto' schrieb eine italienische Zeitung, was zum Teil mit Kafka Eindrücken übereinstimmt. Laut dem deutschen Bericht wurde Koch am 6. Oktober in einem Friedhof in Riva beigesetzt, nachdem seine Leiche die Tage zuvor in der Totenkapelle St. Anna aufgebahrt worden war".

11 [No original] [...] "Gewißheit das eines jener österreichischen Jäger gewesen ist, die um 1800". (SEBALD, 2013, p. 248). 12 [No original] "[...] ja schwarz gewordenen Finger meiner Rechten wie das Zeichen für ein durch nichts auf der Welt mehr auszugleichendes Unglück vor Augen“ (SEBALD, 2013, p. 250). 
entre as histórias separadas no tempo e no espaço ${ }^{13}$. Vejamos o modo como o autor-narrador, por sua vez, preenche essa lacuna e ficcionaliza o que seriam esses dias que Kafka esteve internado no sanatório, em companhia do general e de outros pacientes do Dr. Von Hartungen:

\begin{abstract}
Aliás, à sua direita na mesa senta-se um velho general que permanece calado a maior parte do tempo, mas que de vez em quando faz observações agudas e abissais. Certa feita, erguendo de repente a vista do livro que sempre mantém aberto ao seu lado, ele diz que, pensando bem, um vasto campo de contingências insondáveis se estende entre a lógica do plano de combate e a lógica dos comunicados oficiais, ambos os quais lhe eram conhecidos como a palma da mão. Miudezas que escapam à nossa percepção decidem tudo! Nas grandes batalhas da história mundial tinha sido exatamente assim. Miudezas, mas que pesam tanto quanto cinquenta mil cavalos mortos em Waterloo. Em última instância, tudo era uma questão do peso específico, Stendhal tinha tido uma noção mais precisa disso do que todo o estado-maior, e agora, nos seus dias de velhice, ele virara seu aprendiz, para que não morresse sem algum entendimento. Essa era uma ideia no fundo absurda, que se pode influenciar o curso dos acontecimentos com uma guinada do leme, como o arbítrio, ao passo que de fato tudo era determinado pelas mais complexas relações. (SEBALD, 2008, p. 121-222). ${ }^{14}$
\end{abstract}

Esse trecho traz para o discurso a contingência da vida, a falta de nexo com que caminhos são traçados e interrompidos, e essa falta de razão de alguns acontecimentos atordoa o narrador que, no limiar da loucura e da escrita, das ruínas da guerra e das palavras, expressa seu mal-estar e sua responsabilidade. Ainda é interessante ressaltar que o pathos melancólico comum no discurso do narrador, movido pela ação do olhar e da escuta empática,

13 O estudo W. G. Sebald: Die dialektische Imagination [W. G. Sebald: a imaginação dialética] (2009), de Ben Hutchinson, é pontual para essa pesquisa. O primeiro capítulo do estudo de Hutchinson mostra-se muito relevante, pois nele a pesquisadora tece uma análise da técnica narrativa de Sebald considerando a leitura do texto "O narrador", de Walter Benjamin, e da marginália contida no exemplar da biblioteca particular do autor. Sua proposta busca, especificamente, a partir do confrontamento entre o texto de Benjamin e a função do narrador nas obras de Sebald, uma resposta estética a um conceito filosófico, mesmo reconhecendo o perigo heurístico de incorrer em equívocos ao buscar no referencial teórico as respostas para o resultado estético e, justamente por isso, a pesquisadora vale-se da análise de passagens emblemáticas da obra de Sebald para assegurar sua argumentação. Essas se mostram representativas para a compreensão dos princípios de entrelaçamento [Einschachteln] e de inserção [Einbetten] na obra. A tese de Hutchinson (2009), nesse capítulo, é que esses dois princípios, encontrados no texto de Benjamin, são os dispositivos que estabelecem a dialética nas obras e que mantêm com isso a tensão entre fato e ficção, pois Sebald consegue produzir narrativas de um realismo documental a partir de processos estéticos de ficcionalização dos documentos. Ou seja, independente do quadro de analogias estabelecidas em cada uma das narrativas, elas só podem derivar da subjetividade de um narrador em primeira pessoa para organizar essa montagem. O próprio conceito de entrelaçamento, como define a pesquisadora, está ligado ao de inserção [Einbetten], referindo-se a um tipo de montagem que necessita da mediação de um agente organizador, que saiba a hora de começar e terminar a cadeia de analogias que poderia se estender ad infinitum. E assim, a ficcionalidade não estaria nos documentos utilizados, que são sempre verdadeiros, mas na costura e no corte, pois como observou Hutchinson (Ibid. p. 101), é importante questionar o estatuto do material utilizado, mas principalmente pensar em como esse é organizado. 
deve-se ao modo como o mundo interior do narrador e dos personagens são representados desajustados em relação à realidade do mundo exterior.

O narrador, por exemplo, durante a viagem à Itália, em 1980, sente-se perseguido pelo fantasma da morte e pensa que pode ser a próxima vítima dos assassinos Furlan e Abel, cabeças de uma organização criminosa chamada Ludwig. A inserção dessa história na narrativa é feita a partir da referência ficcional do narrador a uma matéria lida no editorial do Jornal O Gazzettino de Veneza, do dia 4 de novembro de 1980, no qual consta que uma carta em caligrafia rúnica fora recebida pelo periódico, e que nela havia a declaração de um grupo chamado Organizzazione Ludwig, que assumia a responsabilidade por uma série de assassinatos ocorridos em Verona e outras cidades da Itália desde 1977. Nesse editorial que o narrador ficcionalmente atribui ao jornal italiano, são relembradas as mortes violentas de algumas das vítimas, como: o cigano Guerrino Spinelli, que morreu dentro de seu velho carro Alfa-Romeu, após sofrer queimaduras graves devido a um incêndio criminoso; o garçom Luciano Stefanato, encontrado morto com duas facas de cozinha atravessadas na nuca; o jovem Cláudio Costa, viciado em heroína, assassinado com trinta e nove facadas (na obra Vertigem, essa notícia está registrada na página 65). Sebald utiliza a imagem que aparece na primeira página do jornal e na qual está escrito "Organizzazione Ludwig”, integrando a narrativa de Vertigem como prova da assinatura em caligrafia rúnica (p. 64, na edição brasileira; p. 89, na edição alemã). Esse texto que o narrador começa a ler, a princípio para fugir do mal-estar que sentiu ao entrar numa pizzaria na cidade de Verona, agrava ainda mais a sua inquietação. A narrativa volta-se novamente à expressão de sentimentos de vertigem e medo, primeiro causados pelo próprio ambiente da pizzaria, no qual as cores azuis das paredes, as redes de pesca que decoram o lugar e o quadro pendurado próximo ao teto (com a imagem de um navio na crista de uma onda e prestes a mergulhar no abismo) produziram uma sensação de enjoo no narrador - "como uma pessoa mareada se segura à balaustrada" (SEBALD, 2008, p. 64) - e um sentimento desolador de que nunca mais seria possível avistar terra firme. Sobre esse episódio encontramos no espólio do autor uma matéria do jornal Die Zeit, de 5 de dezembro de 1986, intitulada Die Gnadenlosen, de autoria de Erwin Brunner, que traz as referências extraliterárias para esse episódio de Vertigem. Ou seja, a matéria original foi publicada por um jornal alemão e não italiano.

A análise das informações contidas na matéria reforça a afirmativa de que Sebald tem a preocupação de construir suas histórias a partir de fragmentos reais (os nomes dos assassinos e dos assassinados, as datas, o local), conservando a essência de legitimidade que é devedora desse processo cuidadoso de pesquisa, que mobiliza o olhar e a escuta para o que é excêntrico, que se apresenta como desvio ou que se inscreve na violência. O recurso do autor em utilizar jornais, revistas e enciclopédias como fonte de pesquisa e como material estético ocorre também nas demais narrativas, como poderá ser observado no decorrer das análises.

Essa prática torna os documentos de mídia preservados em seu arquivo fontes de narrações de histórias estranhas, tristes, violentas; notícias nas quais se vislumbra os desajustes entre civilidade e natureza, entre vida e morte, entre paz e guerra, entre normalidade e excentricidade. Ou seja, a seleção desses documentos expressa, de algum modo, a preocupação ética do autor-narrador em recolher vestígios das agruras de uma história menor, que 
se escreve na banalidade do cotidiano. A única "falsificação" realizada pelo narrador não interfere na diegese da obra, pois se trata apenas da alteração de uma informação sobre o jornal no qual consta a matéria. No arquivo do autor refere-se a um jornal da Alemanha e na ficcionalização de Vertigem ele é apresentado como um jornal italiano. A alteração refere-se apenas a costura do episódio, que exigia do autor essa transfiguração, já que se trata de um capítulo no qual o narrador viaja pela Itália, mas não invalida a legitimidade dos documentos, o que é um princípio de orientação do trabalho do autor. É pela sensibilidade em perceber o espaço e pelo repertório intelectual que o autor-narrador mobiliza que são criadas as condições para historicizar os objetos encontrados pelo caminho.

Ainda sobre a atmosfera de perseguição que atravessa a narrativa, podemos citar um episódio do capítulo dois, no qual o narrador se sente perseguido por dois homens durante uma visita que faz ao Palácio Giardino Giusti, em Verona. Esses lhe parecem os mesmos gêmeos que ele já havia notado observando-o na parte da manhã, durante o café que tomou na ferrovia, no momento de sua chegada à cidade.

A presença desses estranhos ressoa sentidos tanto na passagem sobre os assassinos Abel e Furlan (que têm seus nomes grifados por Sebald, como podemos perceber nas imagens do jornal acima) como ainda faz eco na própria história de Kafka. Vejamos. Durante uma viagem de ônibus de Desenzano até Riva, o narrador encontra um casal de irmãos idênticos ao escritor Kafka; essa situação é mencionada pelo narrador sem a adição de nenhum documento que comprove o ocorrido, o que torna ainda mais enigmática essa “[...] coincidência altamente improvável” (SEBALD, 2008, p. 74) e, de certo modo, inverte a lógica das provas. Sendo assim, a espectralidade de Kafka é retomada nessas situações a partir do tensionamento do próprio absurdo contido na realidade e as coincidências estranhas parecem funcionar como irrupções do passado no presente. Ainda sobre a influência de Kafka em Sebald, voltamos à circularidade proposta pelo retorno do caçador no último capítulo, uma espécie de Graccus, como já citamos acima, que "sobrevive" à morte pelos rastros de seu uniforme de soldado, que vive no corpo de um manequim, "vivendo" entre as quinquilharias de um sótão. Assim, numa metáfora da fragilidade do tempo transcorrido, do que resta enquanto vestígio da história e da memória, o tecido já velho do uniforme, ao simples toque da mão do narrador, dissolve-se em pó. Ou seja, a dissolução do uniforme do caçador ao simples toque da mão do narrador não se apresenta como uma solução para o mistério construído ainda na infância, mas sim redireciona suas setas, que se voltam para as histórias anteriores, inclusive a história da participação do jovem Henri Beyle como soldado das tropas de Napoleão, durante a batalha de Marengo.

O espaço da ficção em Sebald é, portanto, das relações metonímicas, possível de observar na seguinte declaração do narrador, sobre sua técnica de escrita: "sentei-me a uma mesa perto da porta aberta do terraço, papéis e notas espalhadas ao meu redor, traçando correspondências entre os acontecimentos muito distantes entre si, mas que me pareciam parte da mesma ordem"15 (SEBALD, 2008, p. 76), o que reforça a imagem- conceito de um labirinto contemporâneo (as passagens benjaminianas) como forma e tema das narrativas,

15 [No original] "Ich sa $\beta$ na einem Tisch nahe der offenen Terrassentür, hatte meine Papiere und Aufzeichnungen um mich her ausgebreitet und zog Vebindungslinien zwischen weit auseinanderliegenden Ereignissen, die mir derselben Ordnung anzugehören schienen“. (SEBALD, 2013, p. 106). 
pelo qual a materialidade do real funde-se ao universo subjetivo, produzindo incursões do narrador pelas grandes vias da História coletiva e pelas zonas cinzentas e esfaceladas das histórias individuais. Isso acontece a partir do confrontamento com os materiais fontes, encontrados no arquivo em Marbach, que dão a ver o modo como o material usado como elemento extraliterário passa antes pelo crivo crítico do narrador, que está interessado em explorar a realidade a partir de uma perspectiva melancólica, que reproduza, a partir da inserção dos documentos, uma estrutura estética que exiba o próprio movimento destrutivo da história natural e social, em uma catástrofe sempre anunciada.

A profanação dos arquivos das mídias, no caso dos documentos citados acima, produz discursos no qual o pathos melancólico é constantemente reformulado, expondo diferentes facetas dessa relação fraturada entre o mundo interior (da imaginação) e o mundo exterior (dos fatos e dos fardos da História). É o desencanto do narrador diante do mundo, assombrado por fantasmas de um passado revivido a partir de uma perspectiva traumática, que torna o pathos melancólico um sentimento comum a sua consciência enlutada. Nesse sentido, as imagens de sofrimento dos anjos pintados por Giotto, na capela de Enrico Scrovegni, em Pádua, na Itália, chamam a atenção do narrador de Vertigem, que fica tocado "[...] pelo lamento silencioso erguido havia quase sete séculos pelos anjos que pairavam sobre a infinita desventura"16 (SEBALD, p. 2008, p. 69). As faces enrugadas de dor, as pálpebras cerradas e a boca entreaberta, soltando um grito de dor e lamento, e as mãos unidas do primeiro anjo, em um gesto de fé, benevolência ou mesmo desespero, dão a impressão de anjos visitando uma cena de desgraça, como comenta o narrador, usando a expressão em italiano "Gli angeli visitano la scena della disgrazia" (Op. Cit.).

Figura 3 - Afrescos de Giotto, na capela Enrico Scrovegni, Pádua, Itália.

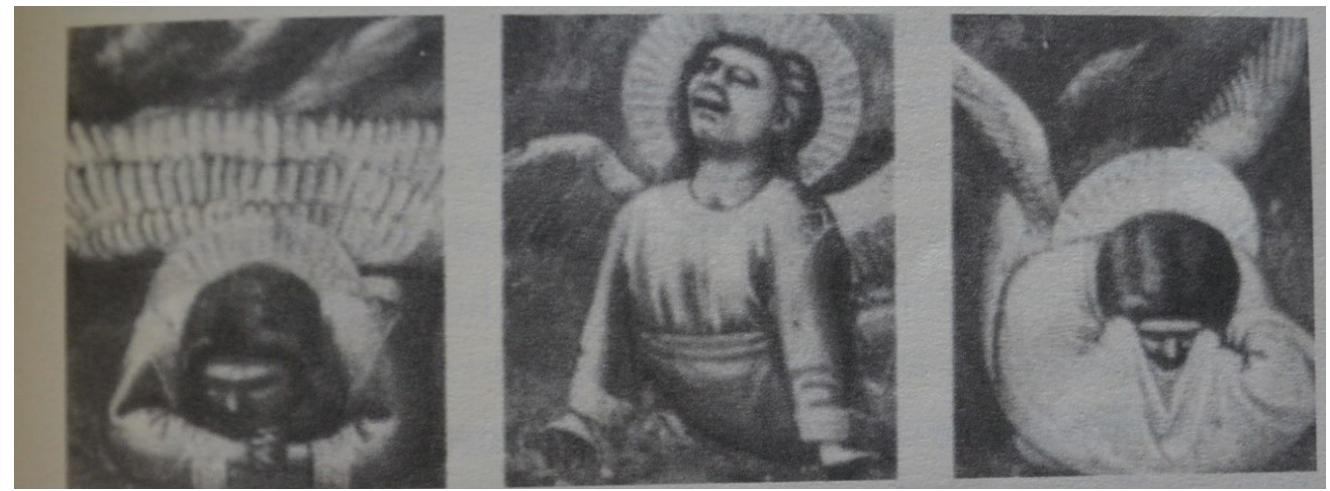

Fonte: Vertigem (SEBALD, 2008, p. 69).

Na literatura de Sebald, portanto, é comum o tensionamento de espaços limiares. O modo como os personagens reais são ficcionalizados a partir de documentos que se ligam a histórias de vidas de carne e osso, estabelece um modelo de representação no qual as fronteiras entre real e imaginário, biografia e autobiografia, vida e morte são diluídas. Mesmo

16 [No original] “[...] siebenhundert jahren von den über dem unendlichen unglück schwebenden engeln erhoben wird“. (SEBALD, 2013, p. 96). 
os personagens literários secundários, se assim for justo denominá-los, como Casanova e Grilpalzer, integrados ao capítulo "Ritorno in patria", são mobilizados pelo narrador como gancho narrativo para as digressões que tece sobre a monumentalidade da arquitetura (do Palácio da Justiça em Veneza) e sobre as incongruências das leis (venezianas).

Desse modo, a materialidade dos documentos (a realidade dos nomes, datas, locais, acontecimentos) torna ainda mais acentuada os processos de fantasmagoria entre Literatura e História, tornando-se um espaço de restituição de histórias menores, no qual o material extraliterário se torna chave para que a própria memória coletiva seja (re)formulada.

\section{REFERÊNCIAS}

HUTCHINSON, Ben. W. G. Sebald: die dialektische imagination. Berlim: De Gruyter, 2009.

NIEHAUS, Michael; ÖHLSCHLÄGER, Claudia. (Org.). W. G. Sebald. Politische archäologie und melancholische bastelei. Berlim: Erich Schmidt, 2006.

NORTHEY, Anthony. Kafka in Riva, 1913. Nene bürcher beitung: literatur und kunst. Freitag, Alemanha, 24 abr. 1987. p. 37-38.

SEBALD, W. G. Schwindel. Gefühle. 8. ed. Frankfurt: Fischer Taschenbuch Verlag, 2013.

Vertigem: sensações. Trad. José Marcos de Macedo. São Paulo: Companhia das Letras, 2008.

SCHÜTTE, Uwe. Por uma germanística “menor”: W. G. Sebald e a "pequena” literatura da periferia austríaca, e de outros lugares. Trad. Cristiane G. Bachmann; Ruth Bohunovsky. In: Cadernos Benjaminianos, 2016, Belo Horizonte, v. 12, p. 9-27. Disponível em: <http://www.periodicos.letras. ufmg.br/index.php/cadernosbenjaminianos/article/view/11544/9973>. Acesso em: 20 jul. 2016. 
